\title{
Exercise in rats does not alter hypothalamic AMP-activated protein
}

\author{
kinase activity
}

\author{
Ulrika Andersson*, Jonas T. Treebak†, Jakob N. Nielsen†, Kirsty L. Smithף, \\ Caroline R. Abbottף, Caroline J. Smallף, David Carling* and Erik A. Richter †\#
}

*Cellular Stress Group, MRC Clinical Sciences Centre, Imperial College London, Hammersmith Campus, DuCane Rd, London W12 ONN, UK, †Copenhagen Muscle Research Centre, Institute of Exercise and Sport Sciences, 13 Universitetsparken, DK-2100 Copenhagen, Denmark and \Endocrine Unit, Imperial College London, Hammersmith Campus, DuCane Rd, London W12 ONN, UK

\# To whom correspondence should be addressed.Email: ERichter@aki.ku.dk

Abbreviations: Acetyl-CoA carboxylase, ACC; AMP-activated protein kinase, AMPK; peptide YY 3-36, PYY $3-36$;

Key words: AMP-activated protein kinase, energy metabolism, exercise, hypothalamus 


\begin{abstract}
Recent studies have demonstrated that AMP-activated protein kinase (AMPK) in the hypothalamus is involved in the regulation of food intake. Because exercise is known to influence appetite and causes substrate depletion it may also influence AMPK in the hypothalamus. Male rats either rested or ran for 30 or $60 \mathrm{~min}$ on a treadmill $(22 \mathrm{~m} / \mathrm{min}, 10 \%$ slope $)$ and were sacrificed immediately after exercise or after 60 min recovery either in the fasted state or after oral gavage with glucose ( $3 \mathrm{~g} / \mathrm{kg}$ body weightbw). Exercise decreased muscle and liver glycogen substantially. Hypothalamic total or $\alpha 2$-associated AMPK activity and phosphorylation state of the AMPK substrate acetyl-CoA carboxylase (ACC) were not changed significantly immediately following treadmill running or during fed or fasted recovery. Plasma grehlin increased $(\mathrm{p}<0.05)$ by $40 \%$ during exercise whereas the concentration of PYY was unchanged. In recovery, glucose feeding increased plasma glucose and insulin concentrations whereas grehlin and PYY decreased to (grehlin) or below (PPY) resting levels. It is concluded that $1 \mathrm{~h}$ of strenuous exercise in rats does not elicit significant changes in hypothalamic AMPK activity despite an increase in plasma ghrelin. Thus, changes in energy metabolism during or after exercise are likely not coordinated by changes in hypothalamic AMPK activity.
\end{abstract}




\section{Introduction}

AMP-activated protein kinase (AMPK) is the downstream component of a protein kinase cascade that plays a key role in regulating energy metabolism [1-3]. AMPK is activated by an increase in the AMP:ATP ratio within the cell, and in response phosphorylates a number of targets leading to a decrease in energy utilising pathways and an increase in energy producing pathways. A number of studies have shown that AMPK activity in skeletal muscle is increased following exercise in both humans and rodents [4-8]. Furthermore, activation of AMPK in resting skeletal muscle increases both glucose uptake and fatty acid oxidation [9] as well as gene expression [10; 11], leading to speculation that AMPK could mediate the increase in these pathways in response to exercise \{Winder, 19993011 /id format ref\}. Recent studies, however, have indicated that genetic deletion of either the $\alpha 1$ or $\alpha 2$ catalytic subunits [12] or the $\gamma 3$ regulatory subunit [13] of AMPK has no effect on contraction-stimulated glucose uptake in skeletal muscle and that AMPK is not required for the increase in GLUT4 expression in response to exercise [14]. The precise physiological significance of AMPK in mediating the effects of exercise on skeletal muscle metabolism therefore remains unclear.

Recent studies have demonstrated that AMPK plays a role in the central regulation of energy metabolism. An exciting advance in the field was the finding that AMPK activity in the hypothalamus is altered by hormones that control feeding e.g. leptin and ghrelin $[15 ; 16]$. Furthermore, inhibition of hypothalamic AMPK leads to reduced food intake [16; 17], whereas activation increases food intake $[15 ; 16]$. Exercise leads to changes in appetite such that appetite is suppressed during strenuous exercise [18; 19] and a short while after exercise whereas increases in appetite after a single bout of exercise are inconsistent (For review see[19]). The mechanism 
behind this exercise-induced change in appetite is not known [19] but could involve changes in hypothalamic AMPK activity which may serve the function of coordinating energy expenditure during exercise with energy intake during or after exercise.

In this study we therefore have therefore investigated whether AMPK activity in the hypothalamus is affected during or after exercise and whether it is influenced by the nutritional status after exercise.

\section{Methods}

\section{Experimental Animals}

All experiments were approved by the Danish Animal Experiments Inspectorate and complied with the Principles of Laboratory Animal Care (National Institutes of Health publication no. 8523, revised 1985). Fifty male Wistar rats weighing $\sim 200$ grams were subjected to three treadmill familiarisation sessions of $15-20$ minutes duration per day leaving one rest day between familiarisation and the experimental day. The animals were divided into the following 5 groups consisting of rats that performed equally well on the treadmill. Group 1 acted as control group while groups $2-5$ performed an exercise bout of varying duration. Group 2 ran for 30 minutes, group 3 ran for 60 minutes, group 4 ran for 60 minutes and rested for 60 minutes in the fasted condition, and group 5 ran for 60 minutes and rested for 60 minutes in the fed state. Immediately following the exercise bout, group 4 received a $1 \mathrm{ml}$ oral gavage of $0.9 \%$ saline solution while group 5 received $1 \mathrm{ml}$ of saline containing $3.5 \mathrm{M}$ glucose resulting in a glucose dose of $3 \mathrm{~g} / \mathrm{kg}$. The night prior to the day of the experiment, rats were semi-fasted and received chow corresponding to 
$50 \%$ of their daily energy expenditure. On the day of the experiment, rats assigned to treadmill running ran at a speed of $22 \mathrm{~m} / \mathrm{min}$ on a 10 degree incline.

\section{Collection of tissue and plasma samples}

Animals were sacrificed by decapitation. Trunk blood was collected together with dissection of the liver and soleus and the red and white part of the gastrocnemius muscle. Brains were immediately removed and the hypothalami block dissected and snap-frozen in liquid nitrogen. Plasma was separated by centrifugation, frozen and stored at $-20^{\circ} \mathrm{C}$ until assay.

\section{Plasma assays}

Samples were assayed in duplicate. Insulin in plasma was assayed using a commercial radio immuno-assay (RIA) using rat insulin as standard (Linco, St. Charles, USA). Ghrelin-like IR was measured with a specific and sensitive RIA as previously described [20]. The antibody used (SC10368 G102 Santa Cruz, CA, USA) recognises both octanoyl and des-octanoyl ghrelin and does not cross-react with any known gastrointestinal or pancreatic peptide hormones. PYY-like IR was measured using a specific and sensitive RIA, as previously described [21]. Glucose in plasma was measured by an ABL system 615 (Radiometer, Copenhagen, Denmark). Muscle and liver glycogen content were measured as glucose residues after acid hydrolysis [22].

\section{AMPK assay}

Frozen tissues (approximately $50 \mathrm{mg}$ ) were homogenised in $0.2 \mathrm{ml}$ ice-cold $50 \mathrm{mM}$ Tris/HCl, $\mathrm{pH}$ 7.5, $50 \mathrm{mM} \mathrm{NaF}, 5 \mathrm{mM}$ Na pyrophosphate, $250 \mathrm{mM}$ sucrose, $1 \mathrm{mM}$ EDTA, $1 \mathrm{mM}$ DTT, $1 \mathrm{mM}$ benzamidine, $0.1 \%(\mathrm{w} / \mathrm{v})$ phenylmethylsulphonylfluoride using an UltraTurax homogeniser $(3 \mathrm{x}$ 
$30 \mathrm{~s}$ bursts). Insoluble material was removed by centrifugation and the resulting supernatant used for immunoprecipitation of AMPK and Western blot analysis. Total AMPK was immunoprecipitated from $100 \mu \mathrm{g}$ protein using an anti-pan $\beta$ antibody [23] bound to protein ASepharose and activity measured by phosphorylation of the SAMS synthetic peptide [24]. AMPK$\alpha 2$ specific activity was determined in immunoprecipitates isolated with an antibody specific for the $\alpha 2$ subunit [25].

\section{Western blot analysis}

Tissue lysates $(40 \mu \mathrm{g})$ were resolved by SDS-PAGE and transferred to polyvinylidene fluoride membranes. ACC phosphorylation was measured with a phospho-ACC specific antibody (Upstate) and detected with an anti-rabbit antibody linked to horse radish peroxidase (Bio-Rad). Blots were developed using enhanced chemiluminescence (Pierce) and quantified using a 16-bit chargedcoupled device cooled camera and Gene Tools software (Syngene, Cambridge, UK).

\section{Statistical analysis}

All variables were analysed by ANOVA followed by post-hoc least significant difference tests. $\mathrm{P}<0.05$ were taken to be significant 


\section{Results}

All of the exercise regimes employed in the study significantly reduced muscle and liver glycogen (Table 1). Administration of an oral glucose dose $(3 \mathrm{~g} / \mathrm{kg})$ following the $1 \mathrm{~h}$ run resulted in a significant increase in tissue glycogen content in red gastrocnemius and liver relative to rats fasted during the $1 \mathrm{~h}$ recovery period. Plasma glucose and insulin levels were not significantly changed by the exercise regime per se, although there was a trend towards decreased insulin levels following the exercise bout. In contrast, as would be predicted, there was a significant increase in both plasma glucose and insulin following the oral dose of glucose (Fig. 1A,B).

Total hypothalamic AMPK activity, measured in immune complexes isolated following immunoprecipitation with a pan- $\beta$ antibody that recognises both $\beta 1$ and $\beta 2$, was not changed by any of the exercise regimes (Fig. 2A). Since it has been reported previously that the predominant change in AMPK activity in the hypothalamus is associated with the $\alpha 2$ isoform we measured AMPK activity in immune complexes isolated with an $\alpha 2$-specific antibody (Fig. 2B). As with total AMPK activity there was no significant change in $\alpha 2$-associated activity. Consistent with the lack of effect of exercise on hypothalamic AMPK activity, there was no significant change in the phosphorylation state of ACC (Fig. 3).

We have previously reported that AMPK activity in the hypothalamus is regulated by hormones that influence feeding: leptin inhibits, whereas ghrelin activates, AMPK [15]. The plasma level of ghrelin increased significantly following the $1 \mathrm{~h}$ run, falling during the $1 \mathrm{~h}$ recovery period. Administration of glucose during the recovery period resulted in the level of ghrelin returning to the control value (Fig. 4A). We were unable to accurately measure plasma leptin levels, which were very low in these animals (data not shown). Another hormone, that like leptin causes a decrease in food intake, is peptide YY 3-36 (PYY $3-36)$ [26]. The concentration of plasma 
$\mathrm{PYY}_{3-36}$ was not significantly altered immediately following exercise. During the $1 \mathrm{~h}$ recovery period, however, the level of PYY $3-36$ was significantly reduced and this was not prevented by the oral glucose dose (Fig. 4B). 


\section{Discussion}

A number of recent studies have shown that AMPK plays a key role in regulating both energy intake and expenditure $[1 ; 3]$. In peripheral tissues, such as skeletal muscle, activation of AMPK switches on energy producing pathways and switches off energy consuming pathways. In the hypothalamus, activation of AMPK leads to increased feeding, thereby increasing energy intake. Conversely, inhibition of AMPK in the hypothalamus reduces food intake. These dual functions of AMPK suggest that it may act to coordinate energy expenditure with energy intake. There is already some evidence that this may be the case in one situation. Leptin activates AMPK in skeletal muscle leading to increased fatty acid oxidation [27], whilst inhibiting AMPK in the hypothalamus leads to decreased food intake $[16 ; 17]$. We were interested to investigate whether exercise could affect AMPK activity in the hypothalamus, thereby providing a potential mechanism for the coordination of energy expenditure and energy intake during or following exercise. For instance, exercise leads to changes in appetite such that appetite is suppressed during strenuous exercise and a short while after exercise [18; 19] whereas increases in appetite after a single bout of exercise are not always found [19]). These changes in appetite could therefore be expected to stem from changes in hypothalamic AMPK activity. However, in this study we did not detect any change in hypothalamic AMPK activity in rats subjected to either 30 minutes or $1 \mathrm{~h}$ treadmill running. Similarly, there was no change in hypothalamic AMPK activity after a $1 \mathrm{~h}$ run followed by a $1 \mathrm{~h}$ recovery period in which the rats were either fasted or given an oral glucose dose. Glycogen levels in muscle and liver were markedly reduced following exercise, indicating that the exercise regime was strenuous and created substrate depletion.

ACC lies downstream of AMPK and we previously reported that ACC phosphorylation correlated with AMPK activity in the hypothalamus in response to treatment with either leptin or 
ghrelin [15]. In the current study, however, we did not observe a change in the phosphorylation state of ACC in the hypothalamus, consistent with the lack of effect of exercise on AMPK activity in this tissue. However, it is possible that different intensities or durations of exercise, or different periods of recovery, could result in changes in hypothalamic AMPK activity. Future studies will have to determine this.

Plasma ghrelin concentrations increased with exercise reaching significance after $60 \mathrm{~min}$ of running. In humans, exercise has been reported not to influence plasma ghrelin levels even at high exercise intensities [28-30]. We are unaware of other published data in which the plasma ghrelin response to exercise has been studied in rats. The reason for the increase of plasma ghrelin with exercise in the present study is not known but may indicate that the present exercise regime caused a larger depletion in substrate depots than in the human studies. In agreement with this assumption, plasma ghrelin concentrations only reached basal levels when recovery was accompanied by glucose feeding and partial restoration of liver and muscle glycogen stores. PYY is a gastrointestinal tract-derived hormone that is released post-prandially in proportion to the amount of calories ingested and leads to a reduction in food intake in rodents and man [26]. In contrast to the effect of exercise on plasma ghrelin concentration, the plasma concentration of PYY did not change during exercise but surprisingly decreased in recovery regardless of the feeding status of the rats. In humans the plasma concentration was also found not to change with exercise [31]. We have previously shown that injection of PYY, despite its actions on food intake, does not change AMPK activity in the rat hypothalamus [15]. 
We reported previously that intraperitoneal injection of ghrelin to rats activates AMPK in the hypothalamus [15]. Plasma ghrelin concentration increased during $1 \mathrm{~h}$ treadmill running, and this may have been expected to increase hypothalamic AMPK activity. However, although significant, the increase in ghrelin following exercise was small and presumably not sufficient to activate AMPK.

In conclusion, although prolonged strenuous exercise in rats leads to increased plasma ghrelin concentrations it does not lead to changes in AMPK activity in the brain during or 1 hour after exercise regardless of the feeding status of the rats after exercise. Changes in appetite induced by exercise are thus unlikely to be due to alterations in hypothalamic AMPK activity and changes in energy metabolism during or after exercise are likely not coordinated by changes in hypothalamic AMPK activity. 


\section{Reference List}

[1] D.Carling, The AMP-activated protein kinase cascade--a unifying system for energy control Trends Biochem.Sci. 29, (2004) 18-24.

[2] D.G.Hardie, J.W.Scott, D.A.Pan, E.R.Hudson, Management of cellular energy by the AMPactivated protein kinase system FEBS Lett. 546, (2003) 113-120.

[3] D.G.Hardie, D.Carling, M.Carlson, The AMP-activated/SNF1 protein kinase subfamily: metabolic sensors of the eukaryotic cell? Annu.Rev.Biochem. 67, (1998) 821-855.

[4] W.Derave, H.Ai, J.Ihlemann, L.A.Witters, S.Kristiansen, E.A.Richter, T.Ploug, Dissociation of AMP-activated protein kinase activation and glucose transport in contracting slowtwitch muscle Diabetes 49, (2000) 1281-1287.

[5] T.Hayashi, M.F.Hirshman, E.J.Kurth, W.W.Winder, L.J.Goodyear, Evidence for 5`AMPactivated protein kinase mediation of the effect of muscle contraction on glucose transport. Diabetes 47, (1998) 1369-1373.

[6] W.W.Winder, D.G.Hardie, Inactivation of acetyl-CoA carboxylase and activation of AMPactivated protein kinase in muscle during exercise Am J Physiol 270, (1996) E299E304.

[7] J.F.Wojtaszewski, P.Nielsen, B.F.Hansen, E.A.Richter, B.Kiens, Isoform-specific and exercise intensity-dependent activation of 5'-AMP-activated protein kinase in human skeletal muscle J Physiol 528 Pt 1, (2000) 221-226.

[8] Z.P.Chen, G.K.McConell, B.J.Michell, R.J.Snow, B.J.Canny, B.E.Kemp, AMPK signaling in contracting human skeletal muscle: acetyl-CoA carboxylase and NO synthase phosphorylation Am.J.Physiol Endocrinol.Metab 279, (2000) E1202-E1206.

[9] G.F.Merrill, E.J.Kurth, D.G.Hardie, W.W.Winder, AICA riboside increases AMP-activated protein kinase, fatty acid oxidation, and glucose uptake in rat muscle Am J Physiol 273, (1997) E1107-E1112.

[10] B.F.Holmes, E.J.Kurth-Kraczek, W.W.Winder, Chronic activation of 5 -amp-activated protein kinase increases glut-4, hexokinase and glycogen in muscle., in: Anonymous, 1999, pp. 379A

[11] W.W.Winder, B.F.Holmes, D.S.Rubink, E.B.Jensen, M.Chen, J.O.Holloszy, Activation of AMP-activated protein kinase increases mitochondrial enzymes in skeletal muscle $\mathrm{J}$ Appl.Physiol 88, (2000) 2219-2226.

[12] S.B.Jørgensen, B.Viollet, F.Andreelli, C.Frøsig, J.Birk, P.Schjerling, S.Vaulont, E.A.Richter, J.F.Wojtaszewski, Knockout of the $\alpha 2$ but not $\alpha 15^{\prime}$ AMP-activated protein kinase isoform abolishes 5-aminoimidazole-4-carboxamide-1-beta-4-ribifuranoside but not 
contraction-induced glucose uptake in skeletal muscle J.Biol.Chem. 279, (2004) 10701079 .

[13] B.R.Barnes, S.Marklund, T.L.Steiler, M.Walter, G.Hjalm, V.Amarger, M.Mahlapuu, Y.Leng, C.Johansson, D.Galuska, K.Lindgren, M.Abrink, D.Stapleton, J.R.Zierath, L.Andersson, The 5'-AMP-activated protein kinase gamma3 isoform has a key role in carbohydrate and lipid metabolism in glycolytic skeletal muscle J.Biol.Chem. 279, (2004) 38441-38447.

[14] B.F.Holmes, D.B.Lang, M.J.Birnbaum, J.Mu, G.L.Dohm, AMP kinase is not required for the GLUT4 response to exercise and denervation in skeletal muscle Am.J.Physiol Endocrinol.Metab 287, (2004) E739-E743.

[15] U.Andersson, K.Filipsson, C.R.Abbott, A.Woods, K.Smith, S.R.Bloom, D.Carling, C.J.Small, AMP-activated protein kinase plays a role in the control of food intake J.Biol.Chem. 279, (2004) 12005-12008.

[16] Y.Minokoshi, T.Alquier, N.Furukawa, Y.B.Kim, A.Lee, B.Xue, J.Mu, F.Foufelle, P.Ferre, M.J.Birnbaum, B.J.Stuck, B.B.Kahn, AMP-kinase regulates food intake by responding to hormonal and nutrient signals in the hypothalamus Nature 428, (2004) 569-574.

[17] E.K.Kim, I.Miller, S.Aja, L.E.Landree, M.Pinn, J.McFadden, F.P.Kuhajda, T.H.Moran, G.V.Ronnett, C75, a fatty acid synthase inhibitor, reduces food intake via hypothalamic AMP-activated protein kinase J.Biol.Chem. 279, (2004) 19970-19976.

[18] N.A.King, V.J.Burley, J.E.Blundell, Exercise-induced suppression of appetite: effects on food intake and implications for energy balance Eur.J.Clin.Nutr. 48, (1994) 715-724.

[19] J.E.Blundell, R.J.Stubbs, D.A.Hughes, S.Whybrow, N.A.King, Cross talk between physical activity and appetite control: does physical activity stimulate appetite? Proc.Nutr.Soc. 62, (2003) 651-661.

[20] N.M.Martin, C.J.Small, A.Sajedi, M.Patterson, M.A.Ghatei, S.R.Bloom, Pre-obese and obese agouti mice are sensitive to the anorectic effects of peptide YY(3-36) but resistant to ghrelin Int.J.Obes.Relat Metab Disord. 28, (2004) 886-893.

[21] R.L.Batterham, M.A.Cohen, S.M.Ellis, C.W.Le Roux, D.J.Withers, G.S.Frost, M.A.Ghatei, S.R.Bloom, Inhibition of food intake in obese subjects by peptide YY3-36 n.Engl.J.Med. 349, (2003) 941-948.

[22] O.H.Lowry, J.V.Passonneau, A flexible system of enzymatic analysis, Academic, New York, 1972

[23] A.Woods, P.C.Cheung, F.C.Smith, M.D.Davison, J.Scott, R.K.Beri, D.Carling, Characterization of AMP-activated protein kinase beta and gamma subunits. Assembly of the heterotrimeric complex in vitro J.Biol.Chem. 271, (1996) 10282-10290. 
[24] S.P.Davies, D.Carling, D.G.Hardie, Tissue distribution of the AMP-activated protein kinase, and lack of activation by cyclic-AMP-dependent protein kinase, studied using a specific and sensitive peptide assay Eur.J.Biochem. 186, (1989) 123-128.

[25] A.Woods, I.Salt, J.Scott, D.G.Hardie, D.Carling, The alpha1 and alpha2 isoforms of the AMPactivated protein kinase have similar activities in rat liver but exhibit differences in substrate specificity in vitro FEBS Lett. 397, (1996) 347-351.

[26] R.L.Batterham, M.A.Cowley, C.J.Small, H.Herzog, M.A.Cohen, C.L.Dakin, A.M.Wren, A.E.Brynes, M.J.Low, M.A.Ghatei, R.D.Cone, S.R.Bloom, Gut hormone PYY(3-36) physiologically inhibits food intake Nature 418, (2002) 650-654.

[27] Y.Minokoshi, Y.B.Kim, O.D.Peroni, L.G.Fryer, C.Muller, D.Carling, B.B.Kahn, Leptin stimulates fatty-acid oxidation by activating AMP-activated protein kinase Nature 415, (2002) 339-343.

[28] R.Dall, J.Kanaley, T.K.Hansen, N.Moller, J.S.Christiansen, H.Hosoda, K.Kangawa, J.O.Jorgensen, Plasma ghrelin levels during exercise in healthy subjects and in growth hormone-deficient patients Eur.J.Endocrinol. 147, (2002) 65-70.

[29] A.Schmidt, C.Maier, G.Schaller, P.Nowotny, M.Bayerle-Eder, B.Buranyi, A.Luger, M.Wolzt, Acute exercise has no effect on ghrelin plasma concentrations Horm.Metab Res. 36, (2004) 174-177.

[30] R.R.Kraemer, R.J.Durand, E.O.Acevedo, L.G.Johnson, G.R.Kraemer, E.P.Hebert, V.D.Castracane, Rigorous running increases growth hormone and insulin-like growth factor-I without altering ghrelin Exp.Biol.Med.(Maywood.) 229, (2004) 240-246.

[31] L.Saelsen, H.B.Andersen, P.Bratholm, N.J.Christensen, Radioimmunoassay of plasma neuropeptide Y using HPLC for separation of related peptides and fragments Scand.J.Clin.Lab Invest 54, (1994) 207-214. 


\section{Acknowledgements}

This study was supported by grants from the Medical Research Council UK and the Wellcome Trust (to DC), the Copenhagen Muscle Research Centre and the Danish Medical Research Council. DC and EAR were jointly supported by an integrated project (contract LSHM-CT-2004005272) from the European Commission. JNN was supported by a postdoctoral fellowship from the Carlsberg Foundation 


\section{Figure Legends}

Figure 1.

Plasma glucose (A) and insulin (B) concentrations during and after exercise. Results shown are the mean \pm S.E.M of 10 animals per group. Statistically significant changes compared to control groups are denoted $*(\mathrm{p}<0.05)$.

Figure 2. Hypothalamic AMPK activity in response to exercise.

Total AMPK activity (A) and AMPK $\alpha 2$-specific activity (B) were determined in immune complexes isolated from $100 \mu \mathrm{g}$ lysate. Results are plotted as the percentage activity relative to the control group (non-exercised) and are the mean \pm S.E.M of 10 aminals per group

Figure 3. Acetyl-CoA carboxylase (ACC) phosphorylation was determined by Western blotting using a phsopho-specific antibody. Blots were quantified and the results plotted as a percentage of the control group (A). Results shown are the mean \pm S.E.M of 10 animals per group. A representative blot for each of the groups is shown in (B). Migration of the $\varepsilon \alpha$ and $\beta$ isoforms of ACC is indicated.

Figure 4. Plasma levels of ghrelin (A) and PYY 3-36 $_{36}$ (B) during and after exercise.

Results shown are the mean \pm S.E.M of 10 animals per group. Statistically significant changes compared to control groups are denoted $*(\mathrm{p}<0.05)$ and between $1 \mathrm{~h}$ run and $1 \mathrm{~h}$ run followed by 1h oral glucose administration by $\dagger(\mathrm{p}<0.05)$. 


\section{Tables.}

\begin{tabular}{lccccc}
\hline & Control & $0.5 \mathrm{~h}$ run & lh run & $\begin{array}{c}\text { lh run }+ \\
1 \mathrm{~h} \text { fast }\end{array}$ & $\begin{array}{c}\text { 1h run }+ \\
\text { 1h glucose }\end{array}$ \\
\hline Gastroc. muscle (white) & $38 \pm 3$ & $22 \pm 2 *$ & $22 \pm 2 *$ & $22 \pm 3^{*}$ & $26 \pm 3^{*}$ \\
Gastroc. muscle (red) & $36 \pm 2$ & $19 \pm 2 * \dagger$ & $15 \pm 2 * \dagger$ & $19 \pm 1 * \dagger$ & $26 \pm 3 *$ \\
$\quad$ Liver & $91 \pm 13$ & $53 \pm 9 *$ & $36 \pm 11 *$ & $25 \pm 4 * \dagger$ & $60 \pm 6 *$ \\
\hline
\end{tabular}

Table 1. Muscle and liver glycogen content ( $\mu \mathrm{mol} / \mathrm{g}$ wet wt). Results are given as mean \pm S.E.M. of 10 animals per group. ${ }^{*} \underline{S}$ significantly from control $(\mathrm{p}<0.05) . \dagger \underline{\text { S}}$ significantly different from $1 \mathrm{~h}$ run $+1 \mathrm{~h}$ glucose. 


\section{Figure 1}

A

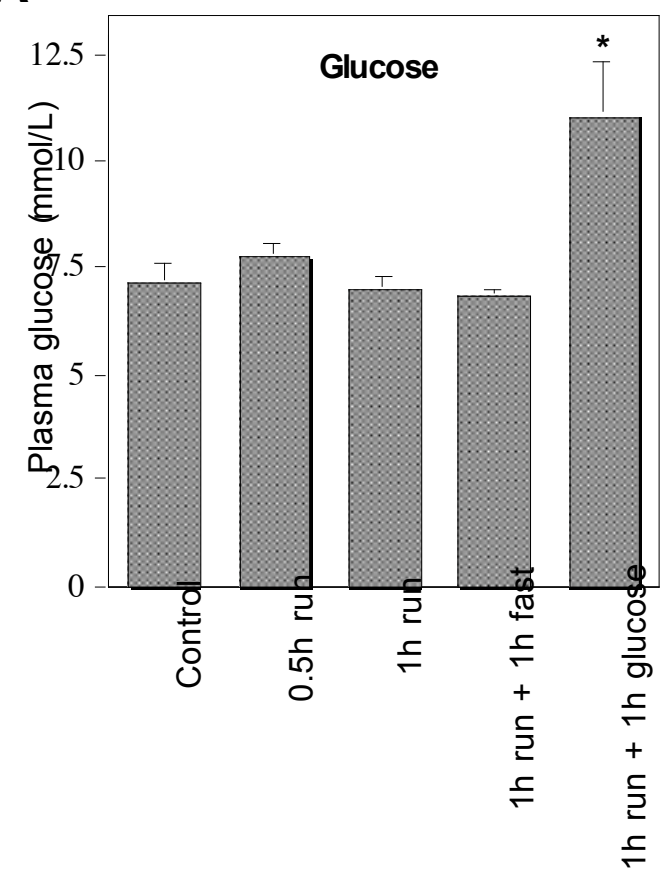

B

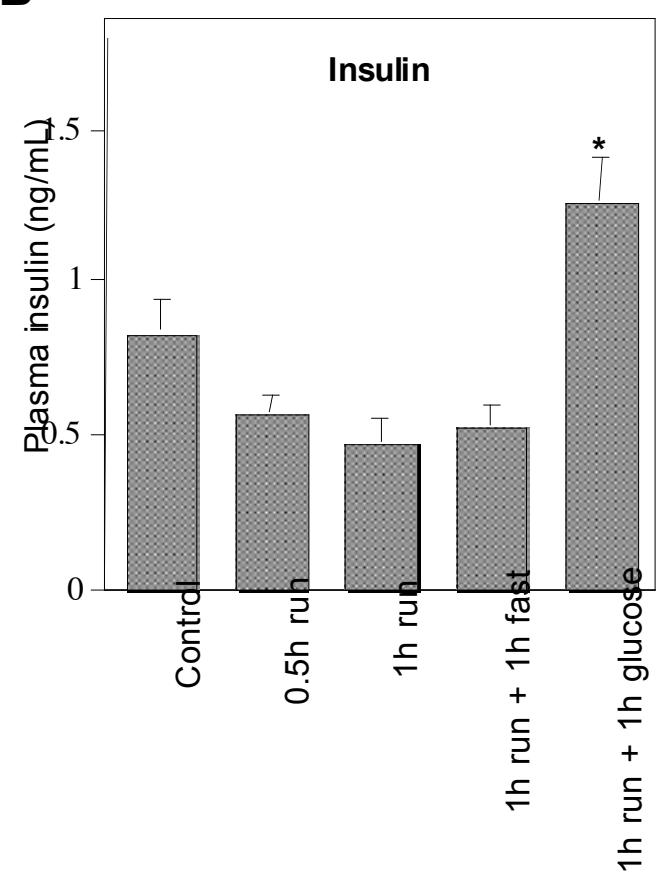


Figure 2

A

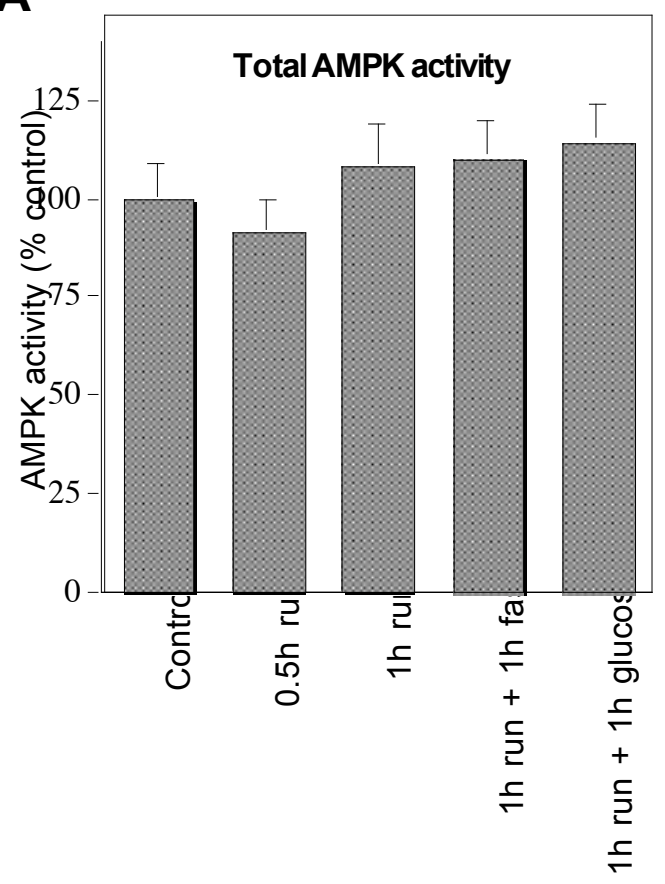

B

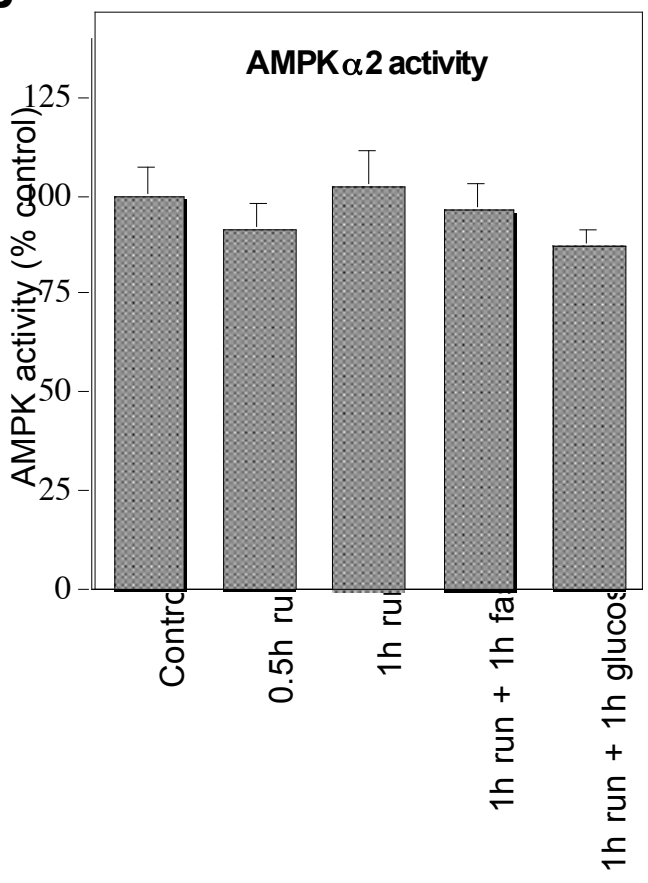


Figure 3

A

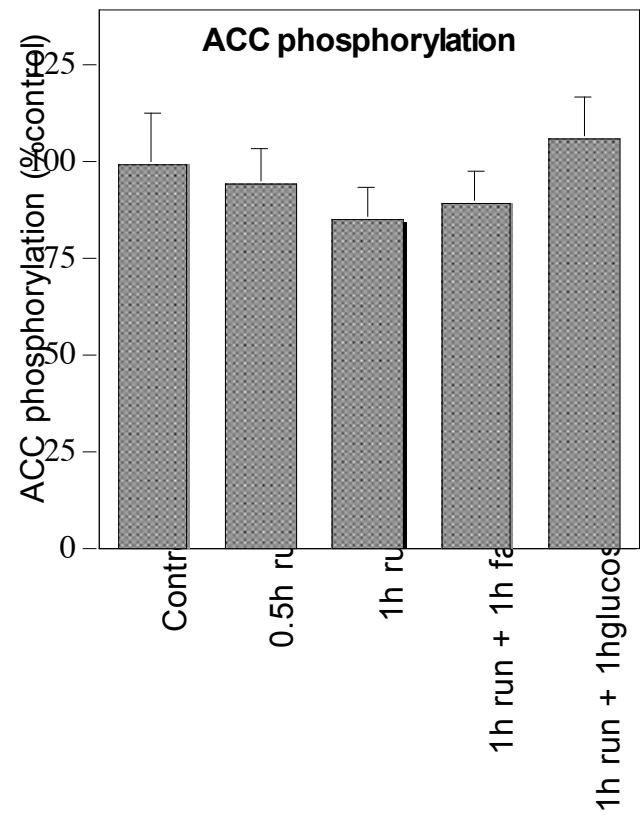

B

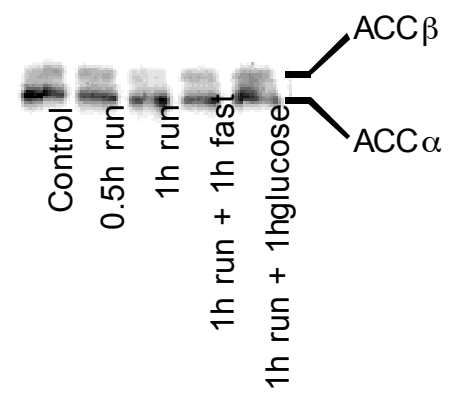


Figure 4 A

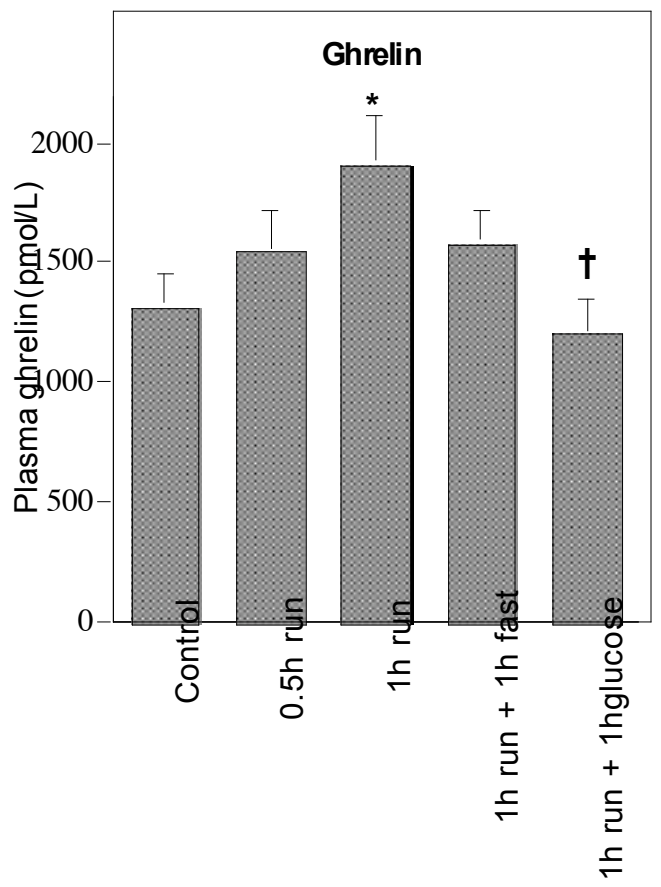

B

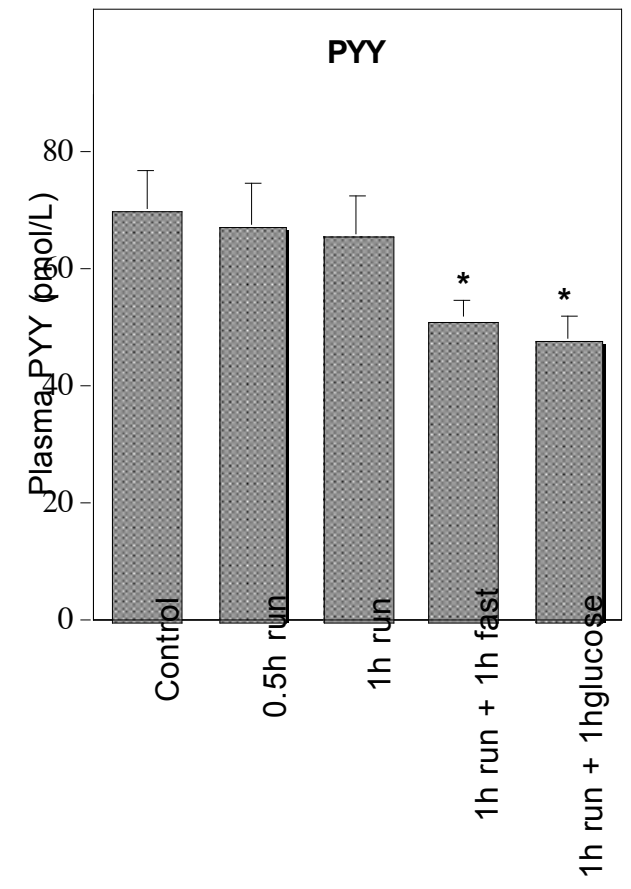

